\title{
Looking past the model species: diversity in gaze-following skills across primates
} Alexandra G Rosati and Brian Hare

Primates must navigate complex social landscapes in their daily lives: gathering information from and about others, competing with others for food and mates, and cooperating to obtain rewards as well. Gaze-following often provides important clues as to what others see, know, or will do; using information about social attention is thus crucial for primates to be competent social actors. However, the cognitive bases of the gaze-following behaviors that primates exhibit appear to vary widely across species. The ultimate challenge of such analyses will therefore be to understand why such different cognitive mechanisms have evolved across species.

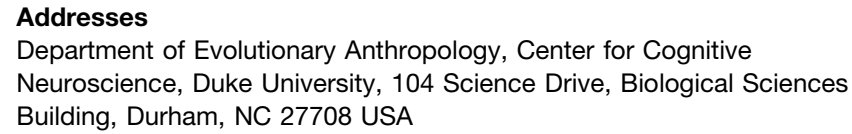

Corresponding author: Rosati, Alexandra G (alexandra.rosati@duke.edu) and Hare, Brian (b.hare@duke.edu)

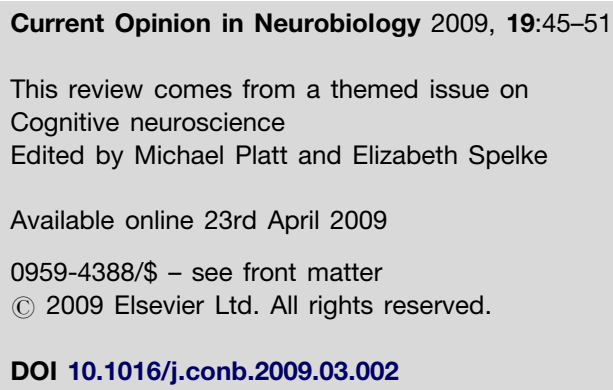

Fundamental to the study of comparative cognition is the idea that many species may exhibit behaviors that appear similar, even if the psychology underlying those behaviors differs across taxa. This distinction is testament to the ingenuity of evolution: the hard problems that animals face get solved, even if the solution is not always the same and some species consequently possess more flexible cognitive mechanisms than others. It also highlights the importance of thinking about primate social interactions not only in the context of behavioral evolution - the special things that primates do - but also in terms of cognitive evolution-the special ways that primates think. We use this framework to analyze the gaze-following behaviors that primates exhibit in naturalistic contexts, the cues they use when co-orienting with others, and the cognitive skills that underlie gaze-following and feed into their social decision making. Research already suggests there is no 'model primate,' as current evidence indicates that different species - including those that are closely related to each other - likely use different types of gaze information and show different levels of understanding when using such information across contexts.

\section{Gaze-following skills are widespread}

Gaze-following - or looking in the direction that others are looking - can result from mechanisms ranging from involuntary capture of attention when others shift where they are looking, to shared attention in which two or more observers know they are jointly looking at the same object or event $\left[1^{\bullet \bullet}\right]$. Whether it involves low level processes or more sophisticated social-cognitive skills, gaze-following allows individuals to apprehend things like food sources, predators, and conspecifics that others have detected in the environment, and thus lets individuals to exploit information that others have acquired about the world to which they might not otherwise have access. Across human and nonhuman primates, this phenomenon has been assessed in a variety of ways, both observationally examining co-orienting behaviors between conspecifics in natural social groups - and experimentally-from the use of simple photographs in which social partners are looking one way or the other, to more complex paradigms that examine whether individuals can follow gaze around barriers and adjust their own position to determine what others are looking at [2].

Converging evidence from these different paradigms indicates that many primates are at least behaviorally responsive to the direction of others' gaze as indicated either by the orientation of their eyes, head, or body. At the most basic level, at least some species from each major primate radiation spontaneously follow the gaze of human experimenters or conspecifics. Hominoids including humans, chimpanzees (Pan troglodytes: $\left[1^{\bullet \bullet}, 3^{\bullet}\right]$ ), and the other great apes (bonobos: Pan paniscus; gorillas: Gorilla gorilla; orangutans: Pongo pygmaeus: $\left.\left[4^{\bullet}, \bullet 5\right]\right)$, Old World monkeys including several species of macaques (Rhesus: Macaca mulatta; stumptail: $M$. arctoides; pigtail: $M$. memstrina $\left[1^{\bullet \bullet}, 6\right]$ ), and mangabeys (Cercocebus atys torquats $\left[1^{\bullet \bullet}\right]$ ); New World monkeys including cotton-top tamarins (Saguinus oedipus: [7]) and common marmosets (Callithrix jacchus [8]), and even some lemur species (ring tailed: Lemur catta $\left[9^{\bullet}\right]$; brown: Eulemur fulvus [10]; black: Eulemur macaco [10]; but see [11]), all follow gaze, at least in some contexts.

This suggests that a basic ability to learn about one's environment from the gaze direction of others is common throughout the primate order. This is especially true among anthropoids (apes and monkeys), the most well 


\begin{tabular}{|c|c|c|c|c|c|}
\hline \multicolumn{6}{|c|}{$\begin{array}{l}\text { Gaze-following methodologies. Studies of gaze-following across primate species broken down by demonstrator species (human o } \\
\text { conspecifics) and type (live demonstrator or photo). Studies that involve both human and conspecifics demonstrators are starred ( }) \text {. }\end{array}$} \\
\hline & Great apes & Lesser apes & Old World monkeys & New World monkeys & Strepsirrhines \\
\hline Human demonstrator & $\begin{array}{l}\text { Chimpanzees: } \\
{\left[3^{\bullet}, 4^{\bullet}, 5^{\bullet \bullet}, 13,14^{\bullet \bullet}\right.} \\
19-21,51,52] \\
\text { Bonobos: }\left[4^{\bullet}, 5^{\bullet \bullet}, 14^{\bullet \bullet}\right] \\
\text { Gorillas: }\left[4^{\bullet}, 5^{\bullet \bullet}, 14^{\bullet \bullet}\right] \\
\text { Orangutans: } \\
{\left[4^{\bullet}, 5^{\bullet \bullet}, 13,14^{\bullet \bullet}\right]}\end{array}$ & & $\begin{array}{l}\text { Longtail macaques: }\left[35^{\circ}\right] \\
\text { Pigtail macaques: }[37,78] \\
\text { Rhesus macaques: }[20,37] \\
\text { Stumptail macaques: }[11,37] \\
\text { Tonkean macaques: }[37]\end{array}$ & $\begin{array}{l}\text { Brown capuchins: [37] } \\
\text { White-faced capuchins: [37] } \\
\text { Squirrel monkey: [37] } \\
\text { Cotton-top tamarins: [7] } \\
\text { Common marmosets: [8] }\end{array}$ & $\begin{array}{l}\text { Black lemurs: }[11,37] \\
\text { Brown lemurs: }[37]\end{array}$ \\
\hline Human photo & Chimpanzees: [54] & $\begin{array}{l}\text { Pileated } \\
\text { gibbons: [53] }\end{array}$ & & & \\
\hline $\begin{array}{l}\text { Conspecific } \\
\text { demonstrator }\end{array}$ & Chimpanzees: $\left[1^{\bullet \bullet}\right]$ & & $\begin{array}{l}\text { Rhesus macaques: }\left[1^{\bullet \bullet}\right] \\
\text { Pigtail macaques: }\left[1^{\bullet \bullet}\right] \\
\text { Stumptail macaques: }\left[1^{\bullet \bullet}\right] \\
\text { Sooty mangabeys: }\left[1^{\bullet \bullet}\right]\end{array}$ & Cotton-top tamarins: $[7]^{*}$ & Ringtailed lemurs: $\left[9^{\circ}\right]$ \\
\hline Conspecific photo & & $\begin{array}{l}\text { Pileated } \\
\text { gibbons: [53] }\end{array}$ & $\begin{array}{l}\text { Rhesus macaques: [6,55] } \\
\text { Diana's monkeys: [56] }\end{array}$ & & $\begin{array}{l}\text { Black lemurs: [10] } \\
\text { Brown lemurs: [10] }\end{array}$ \\
\hline
\end{tabular}

studied group. However, an important caveat must temper this conclusion: the methodologies used to assess gaze-following often differ substantially across studies. For example, most studies use humans as demonstrators rather than conspecifics for pragmatic reasons (see Table 1), and it is possible that some species will respond differently to conspecifics and humans in social-cognitive tasks (however, note that chimpanzees appear to gazefollow at similar rates across studies that used either a conspecific or human demonstrator; $\left.\left[1^{\bullet \bullet}, 12,13\right]\right)$. At the same time, while it is reasonable to assume that animals will show their most sophisticated cognitive skills when interacting with conspecifics, in some cases the use of human demonstrators may actually lead to improved gazefollowing performance. For example, when co-orienting in response to eye movements, the increased visibility of human eyes (e.g. our white sclera are more salient than those of other species) may lead to an enhanced response that does not reflect what animals do in their normal social environments (see below for a discussion of the role of species differences in eye morphology).

\section{Different species use different gaze cues when co-orienting}

Although a variety of species co-orient in response to the gaze of others, there appears to be variation in the type of gaze information that different species use to co-orient. For example, some species appear to follow shifts in eye position alone (e.g. apes $\left[14^{\bullet \bullet}\right]$ ); however, for other species there is only solid evidence that they co-orient in response to shifts in the position of the head or even entire body (e.g. macaques $\left[1^{\bullet}, 6\right]$; capuchins [15]; cottontop tamarins [7]; ring-tailed lemurs [ $9^{\circ}$ ]; black lemurs [10]; brown lemurs [10]; but see [78]). This variation may stem from variability in the information that the eyes carry, partly due to differences in morphology across taxa.
Specifically, the coloration of some primate species results in low contrast between the eyes and face, whereas other species have more visible eyes; this difference might drive reliance on shifts in eye direction as a cue for social attention. Note that human eyes are especially visible owing to our large white sclera, a feature that appears to be exceptional among primates $\left[16^{\bullet \bullet}, 17\right]$.

To test how eye morphology affects the type of cues that different species use to co-orient, Tomasello et al. $\left[14^{\bullet \bullet}\right]$ pitted different types of cues against each other and examined the gaze-following responses of nonhuman great apes and human infants. Owing to unique eye morphology, humans were predicted to be more reliant on eye gaze than other species of apes. Bonobos, chimpanzees, gorillas, and human children witnessed a human experimenter 'looking' at the ceiling with either eyes alone, face alone (with eyes closed), with both face and eyes, with face oriented up but back turned to the subject (i.e. face and eyes not visible). All conditions increased the gaze-following of all four species relative to the control (i.e. the experimenter did not look up); however, nonhuman apes were more dependent on face orientation than eye orientation, whereas children responded strongest to eye direction alone. Thus, while African apes can use eye direction alone as a cue, they are more influenced by face direction than are human children. Studies like this can thus help to differentiate the cues that various species are capable of using versus the cues they prefer to use when available.

Unfortunately, few studies have directly compared the response of subjects within or between species to these different types of gaze cues (i.e. eye, face, head, or body cues) in a systematic fashion. Consequently, in most cases we are only able to make qualitative judgments about 
species' performance across different studies not designed for such comparisons. However, differences in eye and face morphology and species-typical socioecology (e.g., degree of aboreality) predict that species will show significant differences in the degree to which they use various types of gaze information.

\section{Cognitive mechanisms underlying primate gaze-following}

Although gaze-following is widespread in primates, diversity in the types of gaze information that different species utilize suggest that the psychology underlying this behavior differs radically across primates. For example, humans develop the ability to flexibly model the visual perspective and attentional state of others on the basis of multiple types of social information including gaze direction [18]. This process involves reasoning about unseen entities - psychological states - that causally influence the behaviors of others. It is unclear, however, whether most nonhuman primates also use gaze information as a window into other's minds. Although there is now strong evidence that nonhuman apes understand a great deal about the visual perception of others, for the vast majority of other primate species we know very little about the potential cognitive mechanisms underlying social attention (see Table 2). In many cases, it is highly plausible that gaze-following is a fundamentally egocentric process in which animals exploit the behavioral cues provided by others in a largely reflexive manner (e.g. involuntary capture of attention; $\left.\left[1^{\bullet \bullet}\right]\right)$.

The nature of gaze-following in chimpanzees and other nonhuman apes suggests that individuals of these species follow gaze because they understand something about the nature of 'seeing.' Apes not only direct their own gaze in the direction of others but also match their own line of sight to others when physical barriers and distracting objects obscure the target of another's gaze, sometimes requiring them to physically reorient their own bodies $\left[3^{\circ}, 19\right]$. They may also 'check back' with the actor in an attempt to verify the direction of the other's gaze, or quickly stop following the gaze cues when they cannot locate the target of the other's gaze $\left[4^{\bullet}, 20,21\right]$. Additionally, there is extensive evidence that apes modulate their gestures according to other's attention, adjusting gesture frequency on the basis of whether others can see them [22-24], moving in front of people in order to execute gestures in their line of sight [25], and making noises to attract the attention of conspecifics before gesturing in natural contexts [26-30]. Perhaps the strongest evidence that apes have a complex understanding of visual attention, however, comes from studies where subjects must compete with others to obtain food rewards. Chimpanzees use the visual access of conspecifics to determine which specific food to target $\left[31^{\bullet \bullet}\right]$, and also appear to understand how visual perceptions lead to knowledge in others [32]. When competing with humans, chimpanzees prefer to retrieve a piece of food that the human cannot see over one they can see, and even engage in attempts to disguise their interest in the food as they approach it $[33,34]$.

In contrast with apes, many monkey species may follow the gaze of others without possessing the same rich cognitive understanding of their visual perceptions. Gaze-following in these species may result from processes that are largely egocentric or reflexive, with gaze cues capturing attention but not engaging more sophisticated social-cognitive reasoning. However, to date few species have been studied, making it difficult to draw strong conclusions. As always, the majority of work has been conducted with the ubiquitous rhesus macaque, but it is crucial to realize that there is no a priori reason to believe they are in any way representative of non-ape primates given the phylogenetic and socioecological diversity within the primate order (e.g. rhesus have among the least egalitarian social system of any primate). However, research with rhesus macaques has revealed that, like apes, adults quickly habituate to repeated gaze cues when they repeatedly cannot locate the target of another's gaze

\begin{tabular}{|c|c|c|c|c|c|}
\hline \multicolumn{6}{|c|}{$\begin{array}{l}\text { The cognitive bases of gaze-following. Studies addressing gaze-following and related social-cognitive skills across major taxanomic } \\
\text { divisions. Note that in some cases studies find negative results (e.g. }\left[44^{\circ}\right] \text { and [43] fail to find evidence that some monkeys can take the } \\
\text { visual perspective of conspecifics). }\end{array}$} \\
\hline & Great apes & Lesser apes & $\begin{array}{l}\text { Old World } \\
\text { monkeys }\end{array}$ & $\begin{array}{l}\text { New World } \\
\text { monkeys }\end{array}$ & Strepsirrhine \\
\hline Follow head/body orientation cues & {$\left[1^{\bullet \bullet}, 3^{\bullet}, 4^{\bullet}, 5^{\bullet \bullet}, 13,14^{\bullet \bullet}, 20,21,51\right]$} & [53] & {$\left[1^{\bullet \bullet}, 6,11,20,35^{\bullet}, 37,55,56,78\right]$} & {$[7,8,37]$} & {$\left[9^{\bullet}, 10,11,37\right]$} \\
\hline Follow eye orientation cues & {$\left[3^{\bullet}, 13,14^{\bullet \bullet}\right]$} & & [78] & & \\
\hline Follow gaze behind barriers & {$\left[3^{\bullet}, 4^{\bullet}, 5^{\bullet \bullet}, 19,58\right]$} & & & & \\
\hline $\begin{array}{l}\text { Habituate to repeated looks; } \\
\text { check back with demonstrator }\end{array}$ & {$\left[4^{\bullet}, 5^{\bullet}, 20,21\right]$} & & {$\left[20,35^{\circ}\right]$} & & \\
\hline $\begin{array}{l}\text { Use of attentional cues (object } \\
\text { choice and expectancy violation) }\end{array}$ & {$[13,21,58-63]$} & [53] & {$[38,40,57]$} & {$[7,8,15,41,42,79]$} & {$[10]$} \\
\hline $\begin{array}{l}\text { Modification of gestures to account } \\
\text { for attention of observer }\end{array}$ & {$[13,22-29,52,64-69]$} & [70] & & & \\
\hline Visual perspective taking & {$\left[31^{\bullet \bullet}, 32-34,71-75\right]$} & & {$\left[36^{\bullet}, 40,76,77\right]$} & {$\left[43,44^{\circ}\right]$} & \\
\hline
\end{tabular}


$\left[20,35^{\circ}\right]$, and they may even check back to the demonstrator if they do not at first see the target of her gaze [35 $\left.5^{\circ}\right]$. Moreover, competition studies similar to some of those examining chimpanzees indicate that rhesus monkeys are sensitive to the visual access of humans and avoid stealing food from a human who can see them in favor of one who cannot $\left[36^{\circ}\right]$. However, there already is reason to suspect differences between mechanisms underlying chimpanzee and rhesus macaque gaze-following skills. A developmental comparison shows that although adults of both species follow gaze and habituate to repeated looks to an empty target, the tendency to habituate quickly develops over different time scales in the two species [20] and may involve different developmental pathways.

Meanwhile, the few studies that have been conducted with other primates suggest that their co-orienting behaviors are more egocentric and reflexive. For example, some lemur species co-orient with conspecifics during their natural interactions $\left[9^{\bullet}\right]$, but seem less able to follow gaze in experimental contexts [11,37]. In addition, a number of species fail to use gaze information in violation of expectation paradigms that use looking time as a measure of discrimination (e.g. capuchins and squirrel monkeys [41]; but see positive results with cotton-top tamarins [42]), or to locate hidden food in object choice tasks [15,38-40]. Moreover, in food competition paradigms (which demonstrate that chimpanzees understand other's visual perspective) both capuchin monkeys [43] and common marmosets [ $\left.44^{\circ}\right]$, fail to reason about what conspecifics can or cannot see-suggesting that they egocentrically use gaze as a behavioral cue without necessarily taking the visual perspective of others.

Overall then, current evidence suggests that while chimpanzees and probably rhesus macaques know something about what others see, and use this information to guide their own behavioral decisions, other species may not have such a sophisticated understanding of attention or perception in others-even though they gaze-follow in many of the same contexts as chimpanzees and rhesus macaques. Importantly, humans may be unique among primates in their use of social information such as gaze direction in specific contexts such as those involving cooperation and communication $\left[12,14^{\bullet \bullet}\right]$ —suggesting that even nonhuman apes differ from humans in how flexibly they respond to the social attention of others. On the basis of results so far, we therefore predict there will be diversity in the cognitive mechanisms that underlie the gaze-following skills of primates across the order (see Table 2).

\section{Gazing into the future of primate research}

It is an exciting time in the study of primate social cognition because we are making progress in attacking the big questions about gaze-following specifically and social cognition more generally: to what extent are social skills shared across species (and similar or different to those found in humans), and to the extent that differences exist, why do different species vary in their social skills?

The first part of the question is fundamentally a phylogenetic one. While there is a growing literature on nonhuman apes and a few monkey species, little if any research has examined gaze-following skills in some groups of primates (see Tables 1 and 2), including strepsirrhines (e.g. lemurs and lorises), some groups of New World monkeys such as the atelids (e.g. howler, spider, and woolly monkeys), the colobines (e.g. leaf-eating Old World monkeys such as colubus or languars), and the lesser apes (e.g. gibbons and siamangs). As a result, it is still difficult to characterize the phylogenetic origin of gaze-following skills with much precision beyond a few specific clades within the order. Even more valuable than gross comparisons between distantly related species will be comparisons between groups of closely related species (e.g. such as macaque species with more or less egalitarian social systems). Such research will be crucial in determining the distribution of gaze-following skills across primates - and ultimately be crucial for addressing the second part of this question - why these skills evolved.

The second part of the question is an ultimate one, and is the more challenging of the two because it requires reconstructing past events - evolutionary change and the processes that drove it - that cannot be directly observed. There are three main routes to assess the ultimate function of gaze-following skills. First, comparisons of matched pairs of closely related species that differ in a relevant evolutionary variable (e.g. social system, mating system, habitat, etc.) can assess whether such variables predict species differences in cognitive skills. For example, ecological differences such as the degree of arboreality may lead species to depend on more gross bodily cues than eye or head position, as visibility is more limited in dense foliage. Moreover, if gaze-following is important for social competency as we have claimed, then primates living in larger or more complex social groups might be expected to show superior gaze-following skills. Some evidence already suggests that this is the case: although apes all follow gaze, the use of more complex paradigms and sensitive measures of behavioral response has revealed subtle differences in performance. In a direct comparison of the ability nonhuman apes to follow gaze geometrically (around barriers and past distractions) only the African apes (chimpanzees, bonobos, and gorillas) and not the less gregarious and more distantly related orangutans behave like humans $\left[5^{\bullet \bullet}\right]$.

Another important approach to addressing the ultimate question is to examine the context in which a given cognitive skill is used, as this can give clues as to its behavioral function. For example, gaze-following in longtailed macaques increases when a human demonstrator 
looks with a negative emotional facial expression that signals submission $\left[35^{\circ}\right]$. That this behavior is modulated by salient affective cues thus suggests that gaze-following may be most important for some species during specific social contexts, such as times of distress. Furthermore, in rhesus macaques gaze toward social partners appears to be modulated by rank [45]. As rhesus are notable for their despotic social hierarchy, one prediction is therefore that a more egalitarian species of macaques might show a different pattern of gaze-following in response to individuals of varying rank.

Finally, any adaptive explanation for a trait must ultimately show that the trait is both heritable and has a differential impact on reproductive success. This is a high bar to set for studies of slow-breeding primates, but evidence is accumulating that does bear on this issue. First, studies in the wild indicate that the quality of social relationships females have with group mates does impact the survival of their infants [46]. While there is as of yet no direct evidence that any particular social-cognitive ability per sey impacts fitness, this is some of the first evidence that social competency plays an important role in primate reproductive success. Second, studies of domestication in canids indicate that it is possible to select for improved ability to utilize social cues like gaze [47]. Thus, gazefollowing skills probably have a genetic basis that can be shaped by selective pressures, at least in some taxa. Finally, studies examining individual variance in the cognitive skills of primates will allow researchers to examining how gaze-following relates to other socialcognitive abilities [13], and provides a way to address variance in gaze-following both between and within species. For example, neither chimpanzees and orangutans show sex differences in their tendency to follow gaze, in contrast to evolutionary explanations for human sex differences [48,49] proposing that social information is more important for females. Examining sensitivity to gaze information across species, across contexts, and across individuals thus offers a productive avenue to explore the adaptive nature of these social-cognitive skills.

\section{Conclusion}

Taken together, comparative studies of gaze-following in primates provide an important warning for the cognitive sciences: there is no such thing as 'primate social cognition.' Comparative research - although patchy - has increasingly revealed the diversity of primate social psychology, making it more appropriate to talk about 'chimpanzee social cognition,' 'rhesus monkey social cognition,' or 'capuchin monkey social cognition'-some of the very few species that have been studied enough to make generalized claims about their psychology [50]. Such an emphasis on the differences between species quickly presents a serious challenge to research endeavors that use a few model species in hopes of understanding cognitive traits across wide phylogenetic spaces. While a model systems approach has obviously been fruitful, it also has serious limitations. For instance, it is important to recognize that such an approach cannot be used to address ultimate questions about the origins and causes of traitsincluding cognitive skills. As all psychological mechanisms have evolved, and the course of evolution is constrained by pre-existing mechanisms in the brain, a complete understanding of social cognition will require that both the proximate and the ultimate levels are addressed. Thus, we hope that we have piqued interest as to what the causes and origins of social-cognitive mechanisms across primates might be.

\section{References and recommended reading}

Papers of particular interest, published within the period of review, have been highlighted as:

- of special interest

•• of outstanding interest

1. Tomasello M, Call C, Hare B: Five primate species follow the -. visual gaze of conspecifics. Anim Behav 1998, 55:1063-1069. The authors showed that chimpanzees and four species of Old World monkey reliably follow the gaze of conspecifics. This is one of the few gaze-following studies using live conspecifics demonstrators (as opposed to humans or photos of conspecifics).

2. Emery $\mathrm{NJ}$ : The eyes have it: the neuroethology, function, and evolution of social gaze. Neurosci Biobehav Rev 2000, 24:581-601.

3. Povinelli DJ, Eddy TJ: Chimpanzees: joint visual attention.

- Psychol Sci 1996, 7:129-135.

One of the earliest papers examining gaze-following skills in chimpanzees, the authors demonstrated that individuals were able to use both head + eyes and eyes alone as cues to follow gaze. In addition, this study suggested that chimpanzees understand how barriers impede on other's line of sight, indicating that low-level reflexive models of gaze following cannot account for chimpanzees' performance.

4. Braeuer J, Call J, Tomasello M: All great ape species follow gaze - to distant locations and around barriers. J Comp Psychol 2005, 119:145-154.

This study demonstrated that all four species of great ape are able to reliably follow gaze, and in addition reorient their bodies to look around barriers when the humans appeared to look at a target that was not in the line of sight of the subject. These behaviors suggest that hominoids utilize more sophisticated social-cognitive mechanisms to follow gaze than many other species of primate, who may follow gaze in a relatively reflexive manner.

5. Okamoto-Barth S, Call J, Tomasello M: Great apes'

-. understanding of other individuals' line of sight. Psychol Sci 2007, 18:462-468.

This study used a visual obstruction paradigm to examine how the four great apes responded to a more complex gaze-following situation where a human experimenter looked at a barrier that either had a window or was opaque. African apes looked at the target location more in the window condition, and chimpanzees and bonobos in addition were more likely to look in the barrier or produce 'double looks' in the opaque condition. Orangutans, in contrast, did not appear sensitive to the window manipulation, suggesting that even hominoids differ in the flexibility of their gaze-following skills.

6. Emery NJ, Lorincz EN, Perrett DI, Oram MW, Baker Cl: Gaze following and joint attention in rhesus monkeys (Macaca mulatta). J Comp Psychol 1997, 111:286-293.

7. Neiworth JJ, Burman MA, Basile BM, Lickteig MT: Use of experimenter-given cues in visual co-orienting and in an objectchoice task by a New World monkey species, cotton-top tamarins (Sanguinus oedipus). J Comp Psychol 2002, 116:3-11.

8. Burkhart $\mathrm{J}$, Heschl $\mathrm{A}$ : Geometrical gaze following in common marmosets (Callithrix jacchus). J Comp Psychol 2006, 120:120-130. 
9. Shepherd SV, Platt ML: Spontaneous social orienting and gaze - following in ringtailed lemurs (Lemur catta). Anim Cogn 2008 11:13-20.

This study used a gaze-tracking device to show that ring-tailed lemurs reliably co-orient with conspecifics. Notably, ring-tailed lemurs appear to be less successful at following gaze in experimental contexts (e.g., with human demonstrators), suggesting that they may depend on gross body cues to detect the locus of other's attention.

10. Ruiz A, Gomes JC, Roeder JJ, Byrne RW: Gaze following and gaze priming in lemurs. Anim Cogn 2009 doi: 10.1007/s10071008-0202-z.

11. Anderson JR, Mitchell RW: Macaques but not lemurs co-orient visually with humans. Folia Primatol 1999, 70:17-22.

12. Hare $B$, Tomasello $M$ : Chimpanzees are more skillful in competitive than cooperative cognitive tasks. Anim Behav 2004, 68:571-581.

13. Herrmann E, Call J, Hernadez-Lloreda MV, Hare B, Tomasello M: Humans have evolved specialized skills of social cognition: the cultural intelligence hypothesis. Science 2007, 317:1360-1366.

14. Tomasello M, Hare B, Lehmann H, Call J: Reliance on head -. versus eyes in the gaze following of great apes and human infants: the cooperative eye hypothesis. J Hum Evol 2007, 52:314-320.

This study examined how chimpanzees, bonobos, and human infants respond to different kinds of gaze cues, and found that while apes are able to use the eyes alone as a cue to other's gaze direction, they are more reliant on head cues than are humans. One possibility is that humans have evolved unique eye morphology that advertises the direction of an individual's gaze, which might be especially useful in cooperative contexts.

15. Vick SJ, Anderson JR: Learning and limits of use of eye gaze by capuchin monkeys (Cebus apella) in an object-choice task. Comp Psychol 2000, 114:200-207.

16. Kobayashi $\mathrm{H}$, Kohshima S: Unique morphology of the human -• eye. Nature 1997:387

This study of primate morphology indicated that the characteristics of the human eye-a white sclera with high contrast to the iris, along with a horizontal elongation of the visible sclera-are likely unique amongst primates. This morphological difference may be one response that many primates appear to depend on head and body orientation, instead of eyes alone, as a gaze cue-it is difficult for them to detect the direction of their conspecifics eyes.

17. Kobayashi $\mathrm{H}$, Kohshima S: Unique morphology of the human eye and its adaptive meaning: comparative studies on external morphology of the primate eye. J Hum Evol 2001, 40:419-435.

18. Butterworth $\mathrm{G}$, Jarrett $\mathrm{N}$ : What minds have in common is space: spatial mechanisms serving joint visual attention in infancy. $\mathrm{Br}$ J Dev Psychol 1991, 9:55-72.

19. Tomasello M, Hare B, Agnetta B: Chimpanzees, Pan troglydytes, follow gaze direction geometrically. Anim Behav 1999:769-777.

20. Tomasello $M$, Hare $B$, Fogleman $T$ : The ontogeny of gaze following in chimpanzee, Pan troglodytes, and rhesus macaques, Macaca mulatta. Anim Behav 2001 61:335-343.

21. Call J, Hare B, Tomasello M: Chimpanzees gaze following in an object-choice task. Anim Cogn 1998, 1:89-99.

22. Kaminski J, Call J, Tomasello M: Body orientation and face orientation: two factors controlling apes' begging behavior from humans. Anim Cogn 2004, 7:216-223.

23. Hostetter AB, Rseel JL, Freeman H, Hopkins WD: Now you see me, now you don't: evidence that chimpanzees understand the role of the eyes in attention. Anim Cogn 2007, 10:55-62.

24. Povinelli DJ, Eddy TJ: Factors influencing young chimpanzees' (Pan troglodytes) recognition of attention. J Comp Psychol 1996, 110:336-345.

25. Liebal K, Pika S, Call J, Tomasello M: To move or not to move: how apes adjust to the attentional state of others. Interact Stud 2004:5.
26. Liebal K, Call J, Tomasello M: Use of gesture sequences in chimpanzees. Am J Primatol 2004, 64:377-396.

27. Pika S, Liebal K, Tomasello M: Gestural communication in young gorilla (Gorilla gorilla); Gestural repetoire, learning, and use. Am J Primatol 2003:60.

28. Pika S, Liebal K, Tomasello M: Gestural communication in subadult bonobos (Pan paniscus): repertoire and use. Am J Primatol 2005, 65:39-61.

29. Poss SR, Kuhar C, Stoinski TS, Hopkins WD: Differential use of attentional and visual communicative signaling by orangutans (Pongo pygmaeus) and Gorillas (Gorilla gorilla) in response to the attentional status of a human. Am J Primatol 2006, 68:978-992.

30. Call J, Tomasello M: The Gestural Communication of Apes and Monkeys. Erlbaum; 2007.

31. Hare B, Call J, Agnetta B, Tomasello M: Chimpanzees know - what conspecifics do and do not see. Anim Behav 2000 59:771-785.

This was the first experimental study to develop a competition paradigm to examine visual-perspective skills in nonhumans. A subordinate and dominant chimpanzee competed over two pieces of food: however, while the subordinate could see both pieces, and dominant's view of one piece was blocked. When released with a slight head start into the competition area, the subordinate preferentially targeted the piece which the dominant could not see. Variations of this paradigm has since been used to examine social-cognitive abilities in several species, including rhesus, marmosets, capuchins, goats, and corvids.

32. Hare B, Call J, Tomasello M: Do chimpanzees know what conspecifics know? Anim Behav 2001, 61:139-151.

33. Hare B, Call J, Tomasello M: Chimpanzees deceive a human competitor by hiding. Cognition 2006, 101:495-514

34. Melis A, Call J, Tomasello M: Chimpanzees conceal visual and auditory information from others. J Comp Psychol 2006, 120:154-162.

35. Goossens BMA, Dekleva M, Read SM, Sterck EHM, Bolhuis JJ:

- Gaze following in monkeys is modulated by observed facial expression. Anim Behav 2008, 75:1673-1681.

This study indicates that longtailed macaques are more likely to follow gaze when a human looks with a negative facial expression (modeled after the species-specific bare-teeth display) than when they look with a neutral expression. This suggests that gaze-following can be manipulated by the affective response of gazers - a finding that is important for functional interpretations of social-cognitive skills.

36. Flombaum Jl, Santos S: Rhesus monkeys attribute perceptions - to others. Curr Biol 2005, 15:447-452.

This study used a variation of the competition paradigm developed for use with chimpanzees by Hare and colleagues $(200,2001)$ to examine visual perspective-taking abilities in rhesus macaques. Subjects were confronted with two experimenters from which they could steal desirable food. Across situations in which one experimenter's view was block in various ways, rhesus preferred to approach that experimenter over the one who could see their approach.

37. Itakura S: An exploratory study of gaze-monitoring in nonhuman primates. Jpn Psychol Res 1996, 38:174-180.

38. Anderson JR, Montant M, Schmitt D: Rhesus monkeys fail to use gaze direction as an experimenter-given cue in an objectchoice task. Behav Process 1996, 37:47-55.

39. Anderson JR, Sallabery $\mathrm{P}$, Barbier $\mathrm{H}$ : Use of experimenter-given cues during object-choice tasks by capuchin monkeys. Anim Behav 1995, 49:201.

40. Vick SJ, Anderson JR: Use of human visual attention cues by olive baboons (Papio anubis) in a competitive task. J Comp Psychol 2003, 117:209-216.

41. Anderson JR, Kuroshima $\mathrm{H}$, Kuwahata $\mathrm{H}$, Fujita $\mathrm{K}$ : Do squirrel monkeys (Saimiri sciureus) and capuchin monkeys (Cebus apella) predict that looking leads to touching? Anim Cogn 2004, 7:185-192.

42. Santos LR, Hauser MD: How monkeys see the eyes: cotton-top tamarins' reactions to changes in visual attention and action. Anim Cogn 1999, 2:131-139. 
43. Hare B, Addessi E, Call J, Tomasello M, Visalberghi E: Do capuchin monkeys, Cebus apella, know what conspecifics do and do not see? Anim Behav 2003, 65:131-142.

44. Burkhart $J$, Heschl $A$ : Understanding visual access in common

- marmosets, Callithix jacchus: perspective taking or behavior reading? Anim Behav 2007, 73:457-469.

This study used the conspecific competition paradigm developed by Hare and colleagues $(2000,2001)$ to examine visual perspectivetaking in marmosets. Although subordinate individuals were successful at targeting pieces of food that the dominate could not see, follow up experiments suggest it is likely that they were using behavioral cues (such as where the dominate was looking) to do so, rather than reasoning about unseen mental states as chimpanzees appear to do.

45. Shepherd SV, Deaner RO, Platt ML: Social status gates social attention in monkeys. Curr Biol 2006, 16:R119-R120.

46. Silk J, Alberts S, Altmann J: Social bonds of female baboons enhance infant survival. Science 2003, 302:1231-1234.

47. Hare $B$, Tomasello M: Human-like social skills in dogs? Trends Cogn Sci 2005, 9:439-444.

48. Deaner RO, Shepherd SV, Platt ML: Familiarity accentuates gaze cuing in women but not men. Biol Lett 2007, 2:64-67.

49. Bayliss AP, di Pellegrino G, Tipper SP: Sex differences in eye gaze and symbolic cueing of attention. Q J Exp Psychol 2005 58A:631-650.

50. Ghazanfar A, Santos LR: Primate brains in the wild: the sensory bases for social interactions. Nat Rev Neurosci 2004 5:603-616.

51. Itakura S: An exploratory study of gaze-monitoring in nonhuman primates. Jpn Psychol Res 1991, 38:174-180.

52. Tomasello M, Carpenter M: The emergence of social cognition in three young chimpanzees. Monogr Soc Res Child Dev 2005 75: VII-155.

53. Horton KE, Caldwell CA: Visual co-orientation and expectations about attentional orientation in pileated gibbons (Hylobytes pileatus). Behav Process 2006, 72:65-73.

54. Tomonage M, Tanaka M, Matsuzawa T, Myowa-Yamakoshi M, Kosugi D: Development of social cognition in infant chimpanzees (Pan troglodytes): face recognition, smiling, gaze, and the lack of triadic interactions. Jpn Psychol Res 2004 46:227-235.

55. Lorincz EN, Baker $\mathrm{Cl}$, Perrett DI: Visual cues for attention following in rhesus monkeys. In Picture Peception in Animals. Edited by Fargot J. Cambridge University Press; 2000.

56. Scerif G, Gomez JC, Byrne RW: What do Diana monkeys know about the focus of attention of a conspecific? Anim Behav 2004, 68:1239-1247.

57. Vick SJ, Bovet D, Anderson JR: Gaze discrimination learning in olive baboons (Papio anubis). Anim Cogn 2001, 4:1-10.

58. Barth J, Reaux JE, Povinelli DJ: Chimpanzees' (Pan troglodytes) use of gaze cues in object-choice tasks: different methods yield different results. Anim Cogn 2005, 8:84-92.

59. Itakura S, Agnetta B, Hare B, Tomasello M: Chimpanzees use of human and conspecific social cues to locate hidden food. Dev Sci 1999, 2:448-456.

60. Call J, Agnetta B, Tomasello M: Cues that chimpanzees do and do not use to find hidden objects. Anim Cogn 2000, 3:23-34.
61. Braeuer J, Kaminski J, Riedel J, Call J, Tomasello M: Making inferences about the location of hidden food: Social dog, causal ape. J Comp Psychol 2006, 120:38-47.

62. Okamoto-Barth S, Tomonaga M, Tanaka M, Matsuzawa T: Development of using experimenter-given cues in infant chimpanzees: longitudinal changes in behavior and cognitive development. Dev Sci 2008, 11:98-108.

63. Povinelli DJ, Bierschwale DT, Cech C: Comprehension of seeing as a referential act in young children, but not juvenile chimpanzees. Br J Dev Psychol 1999, 17:37-60.

64. Povinelli DJ, Eddy TJ: What young chimpanzees know about seeing. Monogr Soc Res Child 1996, 61:1-152.

65. Theall LA, Povinelli DJ: Do chimpanzees tailor their gestural signals to fit the attentional state of others? Anim Cogn 1999 2.207-214.

66. Povinelli DJ, Theall LA, Reaux JE, Dunphy-Leli S: Chimpanzees spontaneously alter the location of their gestures to match the attentional orientation of others. Anim Behav 2003, 66:71-79.

67. Tomasello M, Call J, Nagell K, Olguin R, Carpenter M: The learning and use of gestural signals by young chimpanzees: a trans-generational study. Primates 1994, 35:137-154.

68. Reaux J, Theall LA, Povinelli DJ: A longitudinal investigation of chimpanzee's understanding of visual perception. Child Dev 1999, 70:275-290

69. Povinelli DJ, Dunphy-Llii S, Reaux JE, Mazza MP: Psychological diversity in chimpanzees and humans: new longitudinal assessments of chimpanzees' understanding of attention. Brain Behav Evol 2002, 59:33-53.

70. Liebal K, Pika S, Tomasello M: Social communication in siamangs (Symphalangus syndactylus): use of gestures and facial expressions. Primates 2003, 45:41-57.

71. Braeuer J, Call J, Tomasello M: Chimpanzees really know what others can see in a competitive situation. Anim Cogn 2007 , 10:439-448.

72. Povinelli DJ, Nelson KE, Boysen ST: Inferences about guessing and knowing by chimpanzees. J Comp Psychol 1990, 104:203-210.

73. Hirata S, Matsuzawa T: Tactics to obtain a hidden food item in chimpanzee pairs (Pan troglodytes). Anim Cogn 2001, 4:285-295.

74. Call J, Tomasello M: A nonverbal false belief task: the performance of children and great apes. Child Dev 1999, 70:381-395.

75. Kaminski J, Call J, Tomasello M: Chimpanzees know what others know, but not what they believe. Cognition 2008 doi: 10.1016/j.cognition.2008.08.010.

76. Povinelli DJ, Parks KA, Novak MA: Do rhesus monkeys (Macaca mulatta) attribute knowledge and ignorance to others? J Comp Psychol 1991, 105:318-325.

77. Kummer $\mathrm{H}$, Anzenberger $\mathrm{G}$, Hemelrijk $\mathrm{CK}$ : Hiding and perspective taking in long-tailed macaques (Maccaca fasicularis). J Comp Psychol 1996, 110:97-102.

78. Ferrari PF, Kohler E, Fogassi L, Gallese V: The ability to follow eye gaze and its emergence during development in macaque monkeys. Proc Natl Acad Sci 2000, 97:13997-14002.

79. Hattori $\mathrm{Y}$, Kuroshima $\mathrm{H}$, Fujita $\mathrm{K}$ : I know you are not looking at me: capuchin monkeys' (Cebus appella) sensitivity to human attentional states. Anim Cogn 2007, 10:141-148. 